\title{
The Use of Porous Silicate Materials with Different Structures for Acetalization of Furfural and 5-Hydroxymethylfurfural by Methanol
}

\author{
Konstantin L. Kaygorodov*a, Vladimir A. Parfenova, \\ Ilya V. Ponomarenko and Alexander S. Samoilo ${ }^{\mathrm{b}}$ \\ anstitute of Chemistry and Chemical Technology SB RAS \\ FRC "Krasnoyarsk Science Center SB RAS" \\ 50/24 Akademgorodok, Krasnoyarsk, 660036, Russia \\ ${ }^{b}$ Siberian Federal University \\ 79 Svobodny, Krasnoyarsk, 660041, Russia
}

Received 14.03.2016, received in revised form 28.05.2016, accepted 19.08.2016

\begin{abstract}
Selective acetalization of furfural and 5-hydroxymethylfurfural by methanol in the presence of silica catalysts was investigated. Catalytic activity of silica materials (MCM-41, SBA-15, and silicagel) in reaction of furfural and 5-hydroxymethylfurfural acetalization by methanol was brought into correlation with its structure and textural properties. Mesostructured silica materials (MCM-41, SBA15) allow obtaining of furfural and 5-hydroxymethylfurfural methylacetals with the 80-95\% yield and up to $98 \%$ selectivity.
\end{abstract}

Keywords: mesostructured silica materials, catalysis, acetalization, furfural, 5-hydroxymethylfurfural, methanol.

DOI: $10.17516 / 1998-2836-2016-9-3-267-280$.

(C) Siberian Federal University. All rights reserved

* Corresponding author E-mail address:kulik@icct.ru 


\title{
Применение пористых силикатных материалов \\ различного строения для ацеталирования фурфурола \\ и 5-гидроксиметилфурфурола метанолом
}

\author{
К.Л. Кайгородов ${ }^{a}$, В.А. Парфенов ${ }^{a}$, \\ И.В. Пономаренко ${ }^{\mathrm{a}}$, А.С. Самойло \\ ${ }^{a}$ Институт химии и химической технологии СО РАН \\ ФИЦ «Красноярский научный иентр СО РАН» \\ Россия, 660036, Красноярск, Академгородок, 50/24 \\ ${ }^{6}$ Сибирский федеральный университет \\ Россия, 660041, Красноярск, Свободный, 79
}

Изучено селективное ацеталирование фурфурола и 5-гидроксиметилфурфурола метанолом в присутствии гетерогенных катализаторов на основе диоксида кремния. Произведено сопоставление каталитической активности силикатных материалов единой химической природы (MCM-41, SBA-15 и силикагель) в реакияях ацеталирования фурфурола и 5-гидроксиметилфурфурола метанолом со структурными и текстурными свойствами катализатора. Мезоструктурированные силикатные материальы (МСM-41, SBA-15) позволяют получить метилачетали фурфурола и 5-гидроксиметилфурфурола с выходами 80-95\% от теоретического с селективностью до $98 \%$.

Ключевые слова: мезоструктурированные силикатные материалы, катализ, ацеталирование, фурфурол, 5-гидроксиметилфурфурол, метанол.

\section{Введение}

Производные фурана - перспективные кандидаты на замену широкого спектра продуктов переработки нефти. Получаемые из возобновляемого растительного сырья фурфурол и 5-гидроксиметилфурфурол (5-ГМФ) входят в число исходных реагентов с высочайшим синтетическим потенциалом [1]. Карбонильные группы в данных соединениях весьма реакционноспособны, что зачастую приводит к необходимости их блокировки при решении синтетических задач. Одними из широко применяемых реакций защиты карбонильной группы в органическом синтезе являются реакции ацеталирования [2]. В качестве катализаторов ацеталирования используются кислоты Брендстеда и Льюса как в гомогенной, так и в гетерогенной фазе [2].

Ацеталирование фурфурола и 5-гидроксиметилфурфурола метанолом перспективно для получения прекурсоров для органического синтеза, например, для получения биодеградируемых поверхностно-активных веществ [3], присадок к моторным топливам $[4,5]$ и фармацевтических препаратов $[6,7]$.

Получение диметилацеталей в основном осуществляется с использованием раствора триметоксиметана (метилового эфира ортомуравьиной кислоты) в метаноле. Наличие триме- 
токсиметана в реакционной массе позволяет смещать равновесие реакции ацеталирования за счет расходования выделяющейся в результате реакции воды на гидролиз триметоксиметана с выделением метанола. Применение растворов триметоксиметана в метаноле экономически менее выгодно, чем использование чистого метанола. Классическая схема получения ацеталей в среде метанола без триметоксиметана требует использования хлороводородной кислоты в качестве катализатора, что вызывает снижение селективности процесса вследствие образования побочных продуктов, обусловленного высокой кислотностью $\mathrm{HCl}$. К тому же требуется тщательная осушка реагентов. Так, ацеталирование фурфурола в среде метанола в присутствии $\mathrm{HCl}$ (мольное соотношение фурфурол/метанол/ $\mathrm{HCl}=100 / 200 / 0,002)$ приводит к диметилацеталю фурфурола с выходом до 60 \% от теоретического [8].

В то же время описано множество гетерогенных катализаторов для реакций защиты функциональных групп, в том числе для реакций ацеталирования [9]. Из описанных гетерогенных катализаторов реакции ацеталирования следует отметить $\mathrm{Ce}^{3+}$-монтмориллонит [10] и силикатный мезопористый материал МСМ-41 [11], позволяющие получить диметилацеталь фурфурола с выходами, близкими к теоретическим, в избытке метанола и без участия триметоксиметана.

Особый интерес представляют данные, опубликованные центром исследования катализаторов Университета Хоккайдо [11]. Применённый в качестве катализатора силикатный мезопористый материал МСМ-41 дал возможность получить диметилацеталь фурфурола с выходом $93 \%$ от теоретического и селективностью 0,989 в среде метанола и без применения триметоксиметана. С точки зрения классического представления о механизме реакций ацеталирования в качестве катализаторов применяются как протолитические, так и льюисовские кислоты. В значительном количестве публикаций об использовании силикатных материалов в качестве катализаторов ацеталирования описываются элементосиликаты, в основном алюмосиликаты, являющиеся кислотами Льюиса [9]. В некоторых работах приведены зависимости каталитической активности от содержания алюминия и кислотности поверхности силикатного материала. Сообщается, что силикаты типа MCM-41 проявляют активность при соотношении $\mathrm{Si} / \mathrm{Al}<100$ [9]. Напротив, в работе [11] сообщается о каталитической активности материала МCM-41 с незначительным содержанием алюминия (соотношение $\mathrm{Si} / \mathrm{Al}=877)$, что соответствует низкой кислотности поверхности [9]. Это обстоятельство позволяет сделать предположение о том, что силикатная поверхность может проявлять каталитическую активность иного характера, а в случае элементосиликатов иметь смешанную природу. Так, в публикациях об исследовании сорбции карбонильных соединений на поверхности силикатов говорится об ослаблении двойной связи $\mathrm{C}=\mathrm{O}$ при сорбции альдегидов и кетонов на поверхности кремнезема $[12,13]$. С другой стороны, имеются сообщения о наличии кислотных центров на силикатной поверхности, обусловленной её микротопологией $[14,15]$. Таким образом, вопрос природы активности силикатной поверхности в реакциях ацеталирования карбонильных соединений можно охарактеризовать как весьма дискуссионный. Более того, гетерогенный характер процесса с участием высокоразвитой поверхности требует рассмотрения вопросов каталитической активности в свете возможных ограничений диффузионного характера. Именно этому аспекту изучения реакций ацеталирования посвящена настоящая статья. В качестве катализаторов используются материалы с единым химическим составом, но с существенно отличающейся архитектурой пористого пространства.

$$
-269-
$$


Таким образом, целью настоящей работы является сопоставление каталитической активности силикатных материалов единой химической природы (MCM-41, SBA-15 и силикагель) в реакциях ацеталирования фурфурола и 5-гидроксиметилфурфурола метанолом со структурными и текстурными свойствами катализатора.

\section{Экспериментальная часть}

\section{Получение и характеризация катализаторов}

В настоящей работе в качестве катализаторов реакции ацеталирования использовались порошки мезопористых мезоструктурированных материалов типа MCM-41 и SBA-15, а также силикагеля, обозначенные в тексте, таблицах и графиках как \#1, \#2 и \#3 соответственно.

Синтез MCM-41 (\#1) осуществлялся взаимодействием тетраэтоксисилана (TEOS) и цетилтриметиламмония бромида в спиртово-аммиачной реакционной среде с последующей стабилизацией силикатной структуры в среде аммиачного буфера при гидротермальных условиях. Более подробно методики синтеза МCM-41 описаны в [16-18]. Материал типа SBA-15 (\#2) синтезирован в кислой среде $(1,6 \mathrm{M} \mathrm{HCl})$ в результате взаимодействия TEOS и триблоксополимера PluronicP123 в соответствии с методикой Жао [19]. Использованный в работе силикагель (\#3) соответствует марке ШСК (шлиховой силикагель крупнопористый). Структурные и текстурные свойства катализаторов представлены в табл. 1.

Рентгеноструктурный анализ катализаторов осуществлялся с помощью дифрактометра X'PertPro (PANalitycal) с излучением $\mathrm{CuK \alpha}_{1,2}$ и полупроводниковым детектором PIXcel и графитовым монохроматором в детектируемом пучке. Сканирование проводилась в угловом интервале $0.4-10.0^{\circ} 2 \Theta$ с шагом $0,026^{\circ}$ и накоплением в точке 1000 с. По рентгенодифракционным данным в результате проведения полнопрофильного анализа (метод Ритвельда [20]) с привлечением модели непрерывной электронной плотности [21] были получены данные, характеризующиеся высокой точностью, о размере элементарной ячейки, диаметре пор и толщине силикатной стенки мезоструктурированных материалов. Уточнение параметров модели осуществлялось методом минимизации разности производных [22].

Регистрация изотерм низкотемпературной адсорбции/десорбции азота производилась на анализаторе удельной поверхности ASAP 2420 (Micromeritics). Текстурные характеристики установлены методами BET, t-plot и BJH (KJS и KJSImproved, для MCM-41 и SBA-15 coответственно). Подготовка образца заключалась в нагревании известной навески материала до $300{ }^{\circ} \mathrm{C}$ под глубоким вакуумом $\left(10^{-2}\right.$ мм рт. ст.) в течение 8 ч. По окончании дегазации и корректировки массы образца образец помещали в аналитическую схему установки. Теплый и холодный свободные объемы ячейки были измерены перед регистрацией изотермы. Дозирование газообразного азота при анализе осуществлялось порциями по 2 и $10 \mathrm{~cm}^{3} /$ г при давлении менее и более $0,001 \mathrm{P} / \mathrm{P}_{0}$ соответственно. $\mathrm{P}_{0}$ измеряли в каждой точке.

\section{Методика синтеза}

Фурфурол квалификации «ч» (ГОСТ 10930-74) перед использованием очищали перегонкой под вакуумом (P = 20 Торр, Ткип $=340 \mathrm{~K})$. 5-Гидроксиметилфурфурол получали согласно описанной ранее методике [23]. Метанол выделяли из раствора № 2 реактива Карла Фишера путем кипячения с обратным холодильником в присутствии избытка металлического цинка с последующей перегонкой. 
Воздушно-сухие порошки катализаторов обрабатывали $0,1 \mathrm{~N}$ раствором азотной кислоты при интенсивном перемешивании в течение 40 мин. Затем отфильтровывали и промывали на фильтре до нейтральной реакции фильтрата. Далее высушивали при $\mathrm{T}=353 \mathrm{~K}$ до постоянного веса.

В 5 мл ( 4 г, $\sim 0,125$ моль) метанола растворяли 0,200 г фурфурола ( 0,002 моль) либо 0,250 г 5-ГМФ ( 0,002 моль). Затем при комнатной температуре к раствору при интенсивном перемешивании добавляли отмеренное количество силикатного материала. Перемешивание продолжали до достижения неизменной концентрации целевого продукта.

\section{Выделение продуктов}

Реакционную массу отфильтровывали, фильтрат разбавляли двойным объёмом насыщенного раствора бикарбоната натрия. Продукты из полученного раствора экстрагировали хлороформом трехкратно равными объёмами. Хлороформный экстракт упаривали на ротационном испарителе до объёма реакционной массы. Полученный раствор подвергали вакуумной перегонке.

\section{Анализ}

Концентрации исходных веществ и продуктов реакции определяли методом газожидкостной хроматографии на хроматографе «Кристалл 2000м» (ПИД, колонка 0,32мм × 30 м, НЖФ SE-30-0,25 мкм), в качестве внутреннего стандарта использовали бензол, объём пробы 3 мкл, калибровку производили по результатам ЯМР-спектроскопии.

Спектры ЯМР записаны на спектрометре Bruker Avance III 600 (600 МГц) с привязкой к дейтериевому сигналу растворителя. В 0,7 мл $\mathrm{CDCl}_{3}$, содержащего 0,05 об. \% тетраметилсилана, растворяли 0,1 мл реакционной массы.

Выход диметилацеталей рассчитывали по формуле $\eta=\frac{C_{A}}{C_{A}^{\text {max }}} \times 100 \%$, где $\mathrm{C}_{\mathrm{A}}$ - концентрация диметилацеталя (моль/л); $\mathrm{C}_{\mathrm{A}}{ }^{\max }$ - максимально возможная концентрация диметилацеталя согласно уравнению реакции (моль/л).

Степень превращения карбонильных соединений рассчитывалипо формуле: $\alpha=\frac{\mathrm{C}_{F}^{0}-\mathrm{C}_{F}}{\mathrm{C}_{F}^{0}} \times 100 \%$, где $\mathrm{C}_{\mathrm{F}}^{0}-$ начальная концентрация карбонильного соединения; $\mathrm{C}_{\mathrm{F}}-$ концентрация карбонильного соединения в реакционной смеси к определенному моменту времени.

Селективность рассчитывали по формуле $S=\eta / \alpha$, где $\eta$ - выход диметилацеталя; $\alpha$ - степень превращения карбонильного соединения.

Для оценки кажущихся констант скорости реакции ацеталирования предположена следующая упрощенная псевдогомогенная кинетическая модель (рис. 1).

На основании предложенной кинетической модели получена следующая система обыкновенных дифференциальных уравнений (ОДУ) первого порядка:

$$
\begin{aligned}
& \frac{d[C]}{d t}=-k_{1}[C]+k_{2}[A]-k_{3}[C] . \\
& \frac{d[A]}{d t}=+k_{1}[C]-k_{2}[A]-k_{4}[A] . \\
& \frac{d[B]}{d t}=+k_{3}[C]+k_{4}[A] .
\end{aligned}
$$




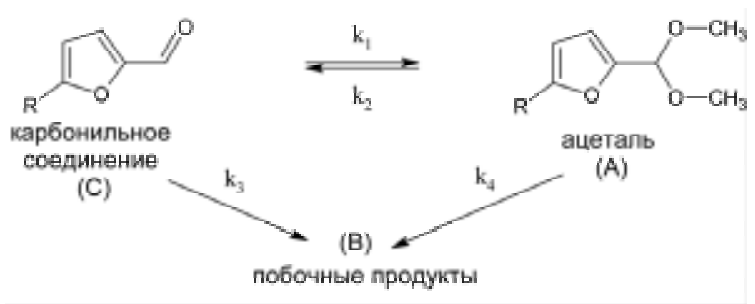

Рис. 1. Схема реакции ацеталирования фурфурола $(\mathrm{R}=\mathrm{H})$ и 5 -гидроксиметилфурфурола $\left(\mathrm{R}=\mathrm{CH}_{2} \mathrm{OH}\right)$ метанолом в рамках предложенной кинетической модели

Кажущиеся константы скорости реакций ацеталирования были рассчитаны с помощью программного комплекса DynaFit (BioKin, Ltd.) [24]. В программном комплексе методом Левенберга-Марквардта производились параметрические аппроксимации экспериментальных данных модельными функциями, построенными путем параллельного численного интегрирования систем ОДУ. Начальные параметры для решения систем ОДУ получены по первым трем точкам зависимостей $\ln (1-\alpha)$ от $\mathrm{t}$, где $\alpha$ - ортонормированная степень превращения карбонильных соединений.

\section{Результаты и обсуждения}

В табл. 1 собраны структурные текстурные свойства использованных в качестве катализаторов силикатных материалов (СМ).

По результатам рентгенографического анализа материалы \#1 и \#2 являются высокоорганизованными мезоструктурированными материалами типа MCM-41 и SBA-15 соответственно. Дифрактограммы представлены на рис. 2. Упорядочение силикатной структуры носит надмолекулярный характер в нанометровом диапазоне размеров. Пространственная группа симметрии P6mm отвечает двумерному упорядочению цилиндрических (гексагональнопризматических) пор по типу пчелиных сот. Установленные в результате полнопрофильного уточнения структурные параметры этих материалов являются типичными. Материал \#3 не структурирован. На молекулярном уровне все материалы аморфны. Согласно результатам газоадсорбционного исследования все материалы сопоставимы по показателю общего объема пор. Материалы \#1 и \#2 проявляют узкое распределения пор по размерам. Материал \#3 обладает широким распределением пор по размерам; максимумов распределения не наблюдается. Установить архитектуру пористой структуры этого материала не представляется возможным. Однако известно, что не более 15 \% общего объема пор материала \#3 образовано порами, размер которых лежит в диапазоне значений 20-100 А и именно эти поры ответственны за формирование поверхности в $120 \mathrm{M}^{2} / \Gamma(73 \%)$ из $165 \mathrm{~m}^{2} / \Gamma$ общей поверхности. Микропорами (поры с диаметром менее $20 \AA$ ) материал \#3 не обладает. Напротив, материал \#2 (SBA-15) обладает микропорами. Непропорционально высокая поверхность материала \#2 в сравнении с материалом \#1 объясняется наличием микропор и шероховатостью стенки мезопор.

Таким образом, в настоящем исследовании в качестве катализаторов реакции ацеталирования используются СМ с существенными отличиями строения пористой структуры и удельной поверхности, но единым химическим составом. 
Таблица 1. Структурные и текстурные свойства силикатных материалов

\begin{tabular}{|c|c|c|c|c|c|c|c|c|}
\hline \multicolumn{2}{|c|}{$\mathrm{CM}$} & $\mathrm{S}, \mathrm{M}^{2} / \Gamma$ & $\mathrm{V}, \mathrm{cm}^{3} / \Gamma$ & $\mu, \mathrm{cm}^{3} / \Gamma$ & $\mathrm{d}(\mathrm{BJH}), \AA$ & $\mathrm{a}, \AA$ & $\mathrm{d}, \AA^{* * *}$ & $\mathrm{w}, \AA$ \\
\hline MCM-41 & $\# 1$ & 959 & 0.89 & 0.00 & $34^{*}$ & 41.8 & 33.7 & 8.1 \\
\hline SBA-15 & $\# 2$ & 634 & 0.96 & 0.07 & $85^{* *}$ & 117.4 & 84.8 & 32.6 \\
\hline ШCK & $\# 3$ & 165 & 0.73 & 0.00 & - & - & - & - \\
\hline
\end{tabular}

* Радиус пор рассчитывался по модифицированному уравнению Кельвина, представленному в [оригKJS].

** Вид уравнения Кельвина для расчета радиуса мезопор материала SBA-15 представлен в работе [KJSImpr].

*** Диаметр пор и толщина стенки определены методом полнопрофильного анализа с применением модели непрерывной электронной плотности.
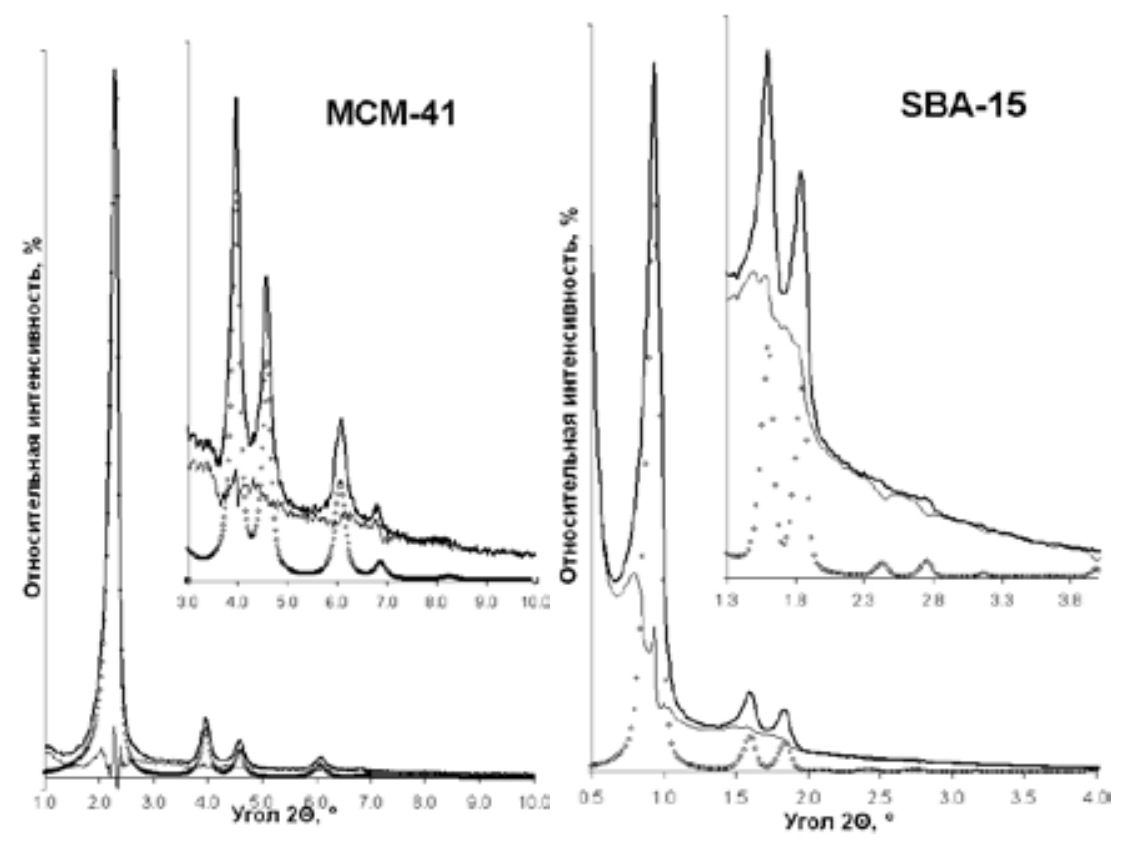

Рис. 2. Дифрактограммы мезоструктурированных материалов

Реакция ацеталирования в присутствии силиката имеет гетерогенный характер. В этой связи было выполнено две серии экспериментов. В опытах 1-6 загрузка материалов была постоянной по массе и составила 0,030 г (табл. 2). Для МСМ-41 эта навеска эквивалентна 29 м $^{2}$ силикатной поверхности, для SBA-15 - 19 м², а для использованного силикагеля - 5 м². В опытах 7-10 навески материалов подбирались из принципа одинаковой площади $\left(29 \mathrm{M}^{2}\right)$. В работе получены кинетические зависимости реакций ацеталирования фурфурола и 5-гидроксиметилфурфурола. Каждый эксперимент состоял из трех повторений трех параллельных опытов.

При метилацеталировании фурфурола основным продуктом является диметилацеталь фурфурола (2-диметоксиметил-фуран). Он представляет собой при нормальных условиях бесцветную маслянистую жидкость с характерным неприятным запахом. $\mathrm{T}_{\text {кип }}=322,4 \pm 0,5$ К (2 Торр), $437 \pm 1,5$ K (750 Торp), ${ }^{1} \mathrm{H} Я M P\left(600\right.$ МГц, $\left.\mathrm{CDCl}_{3}\right): \delta 3,36$ (s, 6H), 5,44 (s, 1H), 6,36 (dd, J = 2,7; 1,8 Гц, 1H), $6,42(\mathrm{dt}, \mathrm{J}=2,7 ; 0,9$ Гц, 1Н), 7,41(dd, J = 1,8; 0,9 Гц, 1Н). Побочные продукты, вероятно, продукты осмоления, индивидуальные соединения не идентифицированы.

$$
-273-
$$


Таблица 2. Загрузки силикатных материалов

\begin{tabular}{|c|c|c|c|c|}
\hline \multirow{2}{*}{ Опыт, номер } & \multirow{2}{*}{$\begin{array}{c}\text { Карбонильное } \\
\text { соединение }\end{array}$} & \multicolumn{3}{|c|}{ Масса СМ, г } \\
\cline { 3 - 5 } & Фурфурол & 0,030 & $\# 2$ & $\# 3$ \\
\hline 1 & Фурфурол & - & - & - \\
\hline 2 & Фурфурол & - & 0,030 & 0,030 \\
\hline 3 & $5-Г М Ф$ & 0,030 & - & - \\
\hline 4 & $5-Г М Ф$ & - & 0,030 & - \\
\hline 5 & $5-Г М Ф$ & - & - & 0,030 \\
\hline 6 & Фурфурол & - & 0,046 & - \\
\hline 7 & Фурфурол & - & - & - \\
\hline 8 & $5-Г М Ф$ & - & 0,046 & 0,176 \\
\hline 9 & $5-Г М Ф$ & - & - & \\
\hline 10 & & & & \\
\hline
\end{tabular}

На рис. 3 приведены кинетические кривые накопления основного продукта реакции в опытах, а в табл. 3 - основные параметры, выражающие результаты реакций метилацеталирования фурфурола.

Кинетические зависимости накопления продуктов и расходования субстрата имеют классическую форму для гетерогенного катализа. На рис. 3 и по данным табл. 3 показано, что наибольший выход целевого продукта и минимальная длительность реакции наблюдается в опыте 1 в результате использования МСM-41 (материал \#1). Количество побочных продуктов также близко к минимальному. В то же время в опыте 2 (с использованием материала SBA-15) была получена более высокая кажущаяся константа скорости. В этом же опыте наблюдается заметное увеличение скорости процесса на начальном этапе, однако на более поздних этапах наблюдается падение выхода и селективности. Эти обстоятельства свидетельствуют о более высокой активности поверхности SBA-15. Однако дальнейшее уменьшение выхода, а также увеличение длительности реакции говорят о дефиците поверхности (опыт 2 в табл. 2). Применение силикагеля в опыте 3 показывает значительно более низкую скорость реакции, выход и селективность.

Как было отмечено, причиной снижения скорости, выхода и селективности может являться дефицит поверхности, в опытах 7 и 8 влияние недостатка площади поверхности было устранено. В результате в опыте 7 выход продукта, селективность и начальная скорость процесса достигли максимальных значений, а количество примесей стало наименьшим. В опыте 8 увеличение навески привело к незначительному увеличению выхода и скорости реакции, но по сравнению с опытами 1 и 7 и константа скорости, и выход остались на полпорядка ниже.

C позиции химического состава все исследованные материалы обладают идентичным строением, и поэтому значительно меньшая каталитическая активность материала \#3 (силикагель) может быть объяснена только с позиции различий в строении силикатной поверхности и пористой структуры. Полагают [14, 15], что кислотно-основные свойства силикатной поверхности определяются наличием на ней силанольных групп, которые ряд авторов разделяют на следующие типы: изолированные, геминальные и вицинальные (рис. 4). 

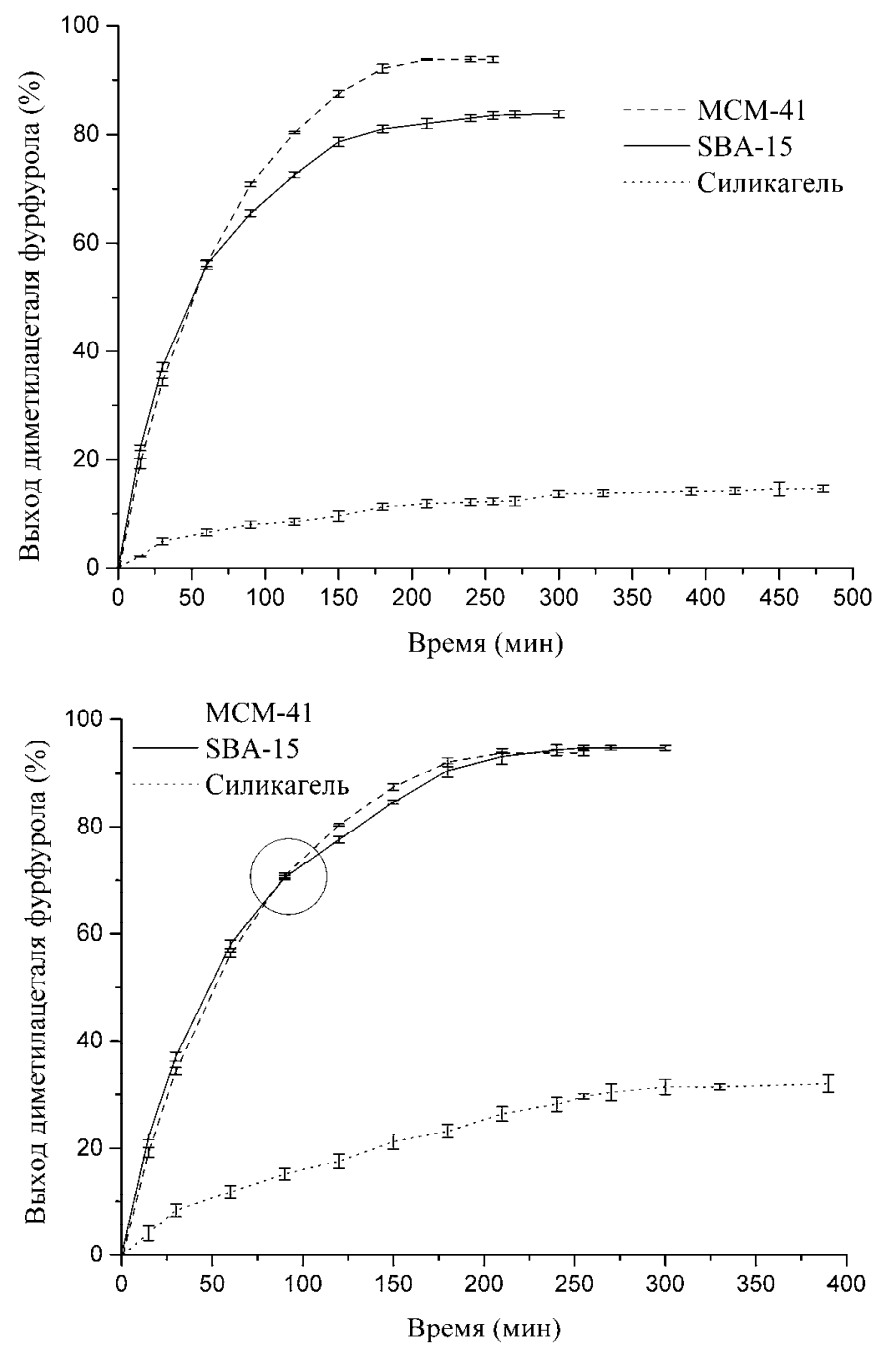

Рис. 3. Кинетические зависимости опытов 1, 2, 3 (вверху) и 1, 7, 8 (внизу)

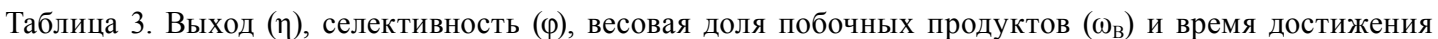
квазиравновесия ( $\left.\mathrm{T}_{\text {const }}\right)$ при метилацеталировании фурфурола

\begin{tabular}{|c|c|c|c|c|c|c|}
\hline Опыт, номер & $\mathrm{CM}$ & $\mathrm{T}_{\text {const }}, \mathrm{Mин}$ & $\mathrm{k}_{1} \cdot 10^{5}, \mathrm{c}^{-1}$ & $\eta, \%$ & $\varphi$ & $\omega_{\mathrm{B}}, \%$ \\
\hline 1 & $\# 1$ & 240 & $25,8 \pm 1,4$ & $93,56 \pm 1,04$ & $0,974 \pm 0,011$ & $1,27 \pm 0,15$ \\
\hline 2 & $\# 2$ & 270 & $31,8 \pm 0,8$ & $85,66 \pm 3,38$ & $0,911 \pm 0,037$ & $2,88 \pm 0,14$ \\
\hline 3 & $\# 3$ & 330 & $7,59 \pm 0,2$ & $24,76 \pm 4,27$ & $0,887 \pm 0,041$ & $5,27 \pm 0,35$ \\
\hline 7 & $\# 2$ & 250 & $35,1 \pm 2$ & $94,24 \pm 1,32$ & $0,976 \pm 0,010$ & $1,19 \pm 0,63$ \\
\hline 8 & $\# 3$ & 300 & $9,88 \pm 0,2$ & $31,64 \pm 4,27$ & $0,849 \pm 0,020$ & $6,32 \pm 0,69$ \\
\hline
\end{tabular}



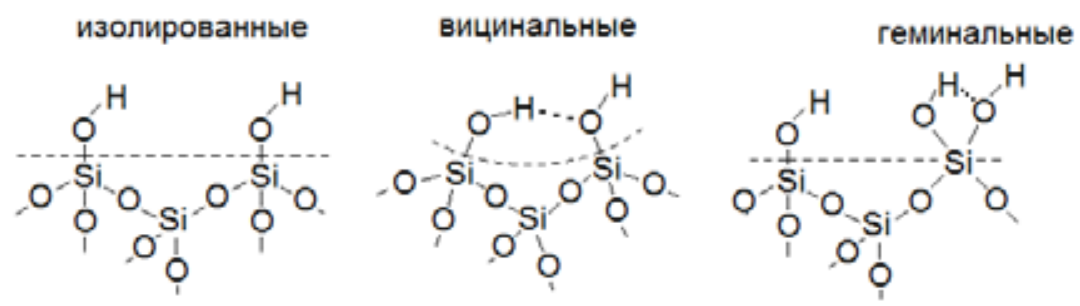

Рис. 4. Типы силанольных групп на поверхности кремнезема

На идеальной силикатной поверхности возможно существование только изолированных групп, однако на вогнутых участках возможно их сближение с образованием вицинальных пар; при наличии дефектов и недостаточной степени конденсации возможно также существование геминальных групп. Образование водородных связей в указанных парах силанольных групп увеличивает их кислотность. Преобладающая отрицательная кривизна поверхности материалов MCM-41 и SBA-15 и высокая доля поверхностных атомов объясняют повышенную концентрацию кислотных центров на поверхности в сравнении с поверхностью силикагеля и обуславливают более высокую каталитическую активность.

Кинетические кривые для опытов 1 и 7 практически совпадают, незначительные различия наблюдаются в большей скорости накопления продукта на начальном этапе и, наоборот, в незначительном отставании на среднем этапе (участок А-В) в опыте 7. Данная особенность может быть связана с микромезопористым строением материала SBA-15, на начальном этапе поверхность микропор может обладать повышенной активностью за счет значительной отрицательной кривизны (поверхности) и, как следствие, относительного сближения силанольных групп. Наблюдаемый в дальнейшем более пологий ход кинетической кривой опыта 7 свидетельствует о снижении активности поверхности. По нашему мнению, это является причиной инактивации поверхности микропор из-за сорбции в их объеме (обратимой или необратимой) части прекурсора или продукта реакции. В целом каталитические характеристики материалов \#1 и \#2 сопоставимы и характеризуют МСМ41 и SBA-15 в качестве эффективных материалов для реализации процесса ацеталирования фурфурола.

Результаты ИК-термогравиметрического анализа СМ по окончании опытов 1-3 показывают суммарную потерю массы воздушно-сухих катализаторов в 69,0, 82,7 и 75,5 \% относительно начального веса соответственно. Если принимать во внимание показатели выхода реакции, такие потери массы не могут быть описаны присутствием основного компонента в порах. Этап отдувки образцов при $40{ }^{\circ} \mathrm{C}$ перед анализом обеспечивает более половины указанной потери массы. Зарегистрированные в ходе анализа ИК-спектры во всех случаях соответствуют смеси воды и фурфурола. Важно заметить, что положения максимумов дифференциальных кривых потери массы по температуре для образцов \#1, \#2 и \#3 образуют ряд 134, 137 и $139{ }^{\circ} \mathrm{C}$. Напротив, температуры достижения постоянной массы составили приблизительно $175^{\circ} \mathrm{C}$ для образцов \#1 и \#2 и $155^{\circ} \mathrm{C}$ для образца \#3. Для некоторых образцов СМ по окончании экспериментов был выполнен термогравиметрический анализ с масс-детектированием. Набор сигналов соответствует смеси воды, фурфурола и следовых количеств метанола. Во-

$$
-276-
$$


прос происхождения обнаруженного на поверхности материалов фурфурола в настоящей работе не исследовался, но в дальнейших работах будет детализован.

По нашему мнению, смещение максимумов на ТГ-кривых потери массы в область высоких температур свидетельствует о более прочной иммобилизации фурфурола (ацеталя фурфурола), а увеличение температуры достижения постоянства массы иллюстрирует диффузионные ограничения отлета гостевых компонентов из пор СМ. Несмотря на наиболее прочное связывание фурфурола с поверхностью силикагеля (\#3), этот процесс, по всей видимости, осуществляется преимущественно в крупных порах, характеризующихся наилучшими транспортными свойствами. Ранее уже отмечалось, что поры размером свыше $100 \AA$ формируют 85 \% объема и, наоборот, поры размером менее $100 \AA$ обеспечивают 73 \% поверхности материала \#3. Устранение дефицита поверхности при переходе от опыта 3 к опыту 8 (табл. 3) незначительно увеличивает выход целевого продукта. В опыте 8 этот показатель составил примерно 32 \% и сопоставим с типичным выходом реакции ацеталирования в этой системе при использовании гомогенного кислотного катализатора [8], в то время как аналогичное количество силикатной поверхности материалов \#1 (опыт 1) и \#2 (опыт 7) обеспечивает выход свыше 93 \%. Таким образом, можно утверждать, что основная доля поверхности силикагеля в реакции ацеталирования фурфурола не участвует в результате ряда причин диффузионной и (или) сорбционной природы, а также в связи со структурными особенностями пористой структуры. Объяснение такого поведения материала \#3 со структурной точки зрения может заключаться в сложной разветвленной и, что наиболее важно, несквозной архитектуре пор материала.

При метилацеталировании 5-ГМФ основным продуктом является диметилацеталь 5-гидроксиметилфурфурола (5-гидроксиметил-2-диметоксиметил-фуран). Он представляет собой при нормальных условиях светло-жёлтую маслянистую жидкость с характерным неприятным запахом. $\mathrm{T}_{\text {кип }}=335,3 \pm 0,5 \mathrm{~K}$ (2 Торр), 474,8 $\pm 0,5 \mathrm{~K}$ (50 Торр). ${ }^{1} \mathrm{H}$-ЯМР (600МГц, $\mathrm{CDCl}_{3}$ ): $\delta 2,82$ (s шир, 1H), 3,32 (s, 6H), 4,58 (s, 2H), 5,29 (s, 1H), 6,19 (d, 1H, J = 3,1 Гц), 6,32 (d, 1H, J = 3,1 Гц).

Также выделены и идентифицированы диметилацеталь 5-метоксиметилфурфурола и 5-метоксиметилфурфурол. Остальные побочные продукты, вероятно, являются продуктами осмоления, индивидуальные соединения не идентифицированы. Диметилацеталь 5-метоксиметилфурфурола (2-диметоксиметил-5-метоксиметил-фуран), светло-желтая маслянистая жидкость с характерным неприятным запахом, $\mathrm{T}_{\text {кип }}=305,6 \pm 0,5 \mathrm{~K}$ (2 Topp), ${ }^{1} \mathrm{H}-\mathrm{NMR}\left(600 \mathrm{MHz}, \mathrm{CDCl}_{3}\right): \delta$ 3,32 (s, 3H), 3,34 (s, 6H), 4,46 (s, 2H), 5,38 (s, 1H), 6,23 (d, 1H, J = 3,1 Hz), 6,30 (d, 1H, J = 3,1Hz), 5-метоксиметилфурфурол, светло-желтая маслянистая жидкость с характерным неприятным запахом, $\mathrm{T}_{\text {кип }}=343,0 \pm 0,5 \mathrm{~K}$ (2 Торр), ${ }_{1}^{1} \mathrm{H}-Я \mathrm{MP}\left(600 \mathrm{MГц,} \mathrm{CDCl}_{3}\right): \delta 3,41$ (s, 3H), 4,48 (s, 2H), 6,52 (d, $1 \mathrm{H}, \mathrm{J}=3,2$ Гц), 7,21 (d, 1H, J = 3,6 Гц), 9,61 (s, 1H).

В табл. 4 приведены параметры, выражающие основные результаты реакций метилацеталирования 5-гидроксиметилфурфурола.

Анализ изменений полученных значений основных численных характеристик реакционной системы процесса ацеталирования 5-ГМФ (табл. 4) в зависимости от типа СМ приводит к заключениям, во многом подобным представленным выше. Отмечаем более высокую реакционную способность 5-ГМФ, о чем свидетельствует рост значений констант 


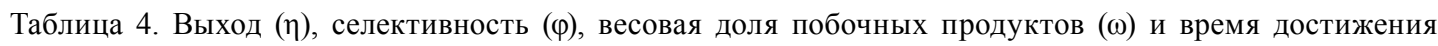
квазиравновесия $\left(\mathrm{T}_{\text {const }}\right)$ при метилацеталировании 5-гидроксиметилфурфурола

\begin{tabular}{|c|c|c|c|c|c|c|c|c|}
\hline \multirow{2}{*}{$\begin{array}{c}\text { Опыт, } \\
\text { номер }\end{array}$} & $\mathrm{CM}$ & \multirow{2}{*}{$\begin{array}{c}\mathrm{T}_{\text {const }}, \\
\text { мин }\end{array}$} & \multirow{2}{*}{$\begin{array}{c}\mathrm{k}_{1} \cdot 10^{5}, \\
\mathrm{c}^{-1}\end{array}$} & \multirow{2}{*}{$\%, \%$} & \multirow{2}{*}{$\varphi$} & \multicolumn{3}{|c|}{ Доля побочных продуктов $\omega, \%$} \\
\cline { 7 - 9 } & & & & & общая & $\mathrm{A}$ & Б \\
\hline 4 & $\# 1$ & 200 & $48,9 \pm 1,1$ & $89,4 \pm 0,5$ & $0,915 \pm 0,011$ & $2,11 \pm 0,11$ & $0,63 \pm 0,06$ & $0,27 \pm 0,08$ \\
\hline 5 & $\# 2$ & 180 & $63,6 \pm 1,5$ & $80,9 \pm 0,4$ & $0,900 \pm 0,017$ & $3,83 \pm 0,19$ & $1,07 \pm 0,04$ & $0,2 \pm 0,3$ \\
\hline 6 & $\# 3$ & 390 & $6,1 \pm 0,3$ & $14,6 \pm 0,7$ & $0,825 \pm 0,014$ & $6,4 \pm 0,9$ & $1,70 \pm 0,17$ & $2,3 \pm 1,1$ \\
\hline 9 & $\# 2$ & 150 & $71,3 \pm 0,6$ & $87,8 \pm 0,4$ & $0,91 \pm 0,03$ & $2,44 \pm 0,12$ & $1,10 \pm 0,02$ & $0,34 \pm 0,18$ \\
\hline 10 & $\# 3$ & 400 & $12,7 \pm 2,2$ & $39,0 \pm 0,7$ & $0,70 \pm 0,06$ & $6,9 \pm 0,8$ & $1,20 \pm 0,12$ & $3,4 \pm 1,2$ \\
\hline
\end{tabular}

* А) 2-диметоксиметил-5-метоксиметил-фуран; Б) 5-метоксиметилфурфурол.

и сокращение длительности, необходимой для достижения постоянства состава реакционной смеси (табл. 4).

С другой стороны, наблюдается уменьшение селективности процесса и общего выхода ацеталя. Некоторые примеси были выделены и идентифицированы. Это обстоятельство предположительно может быть связано с ростом длительности иммобилизации 5-ГМФ на поверхности СМ относительно фурфурола. Данное предположение находит дополнительное подтверждение в связи с высокой склонностью этого соединения к осмолению, обнаруженному при проведении термогравиметрического анализа.

\section{Заключение}

Выполненные исследования показывают высокую активность поверхности силикатных материалов в реакции ацеталирования фурфурола и 5-гидроксиметилфурфурола метанолом. Гетерогенный состав системы заставляет рассматривать процесс в свете факторов диффузионного характера. В частности, высокие показатели выхода целевого продукта в реакциях с участием мезоструктурированных СМ объясняются высокой доступностью всей внутренней поверхности материала. Полагаем, что селективность процесса определяется скоростями сорбции-десорбции прекурсора и продукта реакции на поверхности материала. Значения кажущихся констант скорости, оцененные на начальном этапе реакции, позволяют ранжировать материалы по активности их единичной поверхности. Наилучшие показатели наблюдаются для материала типа SBA-15. Дальнейшие исследования в рамках данной реакционной системы будут направлены на оценку скорости сорбции прекурсора на поверхности СM, а также будут описаны особенности деградации и регенерации катализатора при многократном последовательном использовании.

\section{Список литературы}

1. Werpy G., Petersen T. Top Value Added Chemicals from Biomass Volume I: Results of Screening for Potential Candidates from Sugars and Synthesis Gas. Oak Ridge, TN, USA: U.S. Department of Energy, 2004. 76 p.

2. Wuts P. G. M., Greene T. W. Greene's Protective Groups in Organic Synthesis. Hoboken, NJ, USA: John Wiley \& Sons, Inc., 2006. 1112 p. 
3. Arias K.S., Al-Resayes S.I., Climent M.J., Corma A., Iborra S. From biomass to chemicals: Synthesis of precursors of biodegradable surfactants from 5-hydroxymethylfurfural.ChemSusChem 2013. Vol. 6(1). P. 123-1313.

4. Wegenhart B. L., Liu S., Thom M., Stanley D., Abu-Omar M. M. Solvent-free methods for making acetals derived from glycerol and furfural and their use as a biodiesel fuel component.ACS Catalysis 2012. Vol. 2(12). P. 2524-2530.

5. Liu D., Chen E. Y. X. Integrated catalytic process for biomass conversion and upgrading to C12 furoin and alkane fuel.ACS Catalysis 2014.Vol. 4(5). P. 1302-1310.

6. Cottier L., Descotes G., Soro Y. Synthesis of acetylated ranunculindiastereoisomers and deltaglucosyloxy-gamma-oxo esters from alpha or beta glucosylmethylfurfural.Journal of Carbohydrate Chemistry 2005.Vol. 24(1). P. 55-71.

7. Bowers K. G., Mann J. Oxyallyls in synthesis: Preparation of tricyclic thromboxane $A_{2}$ analogues.Tetrahedron Letters 1985.Vol. 26(36). P. 4411-4412.

8. Adams E. W., Adkins H. The Relation Of Structure, Affinity And Reactivity In Acetal Formation.I.Journal of the American Chemical Society 1925.Vol. 47(5). P. 1368-1381.

9. Sartori G., Ballini R., Bigi F., Bosica G., Maggi R., Righi P. Protection (and Deprotection) of Functional Groups in Organic Synthesis by Heterogeneous Catalysis. Chemical Reviews 2004. Vol. 104(1). P. 199-250.

10. Tateiwa J., Horiuchi H., Uemura S. $\mathrm{Ce}^{3+}$-Exchanged Montmorillonite ( $\mathrm{Ce}^{3+}$-Mont) as a Useful Substrate-Selective Acetalization Catalyst.The Journal of Organic Chemistry 1995.Vol. 60. P. 40394043.

11. Tanaka Y., Sawamura N., Iwamoto M. Highly effective acetalization of aldehydes and ketones with methanol on siliceous mesoporous material.Tetrahedron Letters 1998.vol. 39(51). P. 9457-9460.

12. Anthony L. J., Holland R. A., Heffner S. A. Interactions of aldehydes and ketones with the surface of fused silica capillary columns. Journal of High Resolution Chromatography 1988. Vol. 11. P. 167-172.

13. ParidaS. K., Dash S., Patel S., Mishra B.K. Adsorption of organic molecules on silica surface. Advances in Colloid and Interface Science 2006. Vol. 121(1-3). P. 77-110.

14. Чукин Г.Д. Химия поверхности и строение дисперсного кремнезёма. М.: Типография Паладин, ООО «Принта», 2008. - 172 с. [Chukin G.D.Surface chemistry and structure of the dispersed silica. Moscow: Tipografia Paladin, OOO "Printa”, 2008. 172 p. (In Russ.)]

15. Чуйко А. Строение и химия поверхности кремнезема. Киев: Наукова думка, 2007. 347 c. [ChuikoA. Structureand surface chemistry of the silica. Kyev: Naukova dumka, 2007. 347 p. (In Russ.)]

16. Патент 2287485 РФ. Белоусов О.В., Парфёнов В.А., Соловьев Л.А., Кирик С.Д. Способ ускоренного получения мезопористых мезоструктурированных силикатных материалов типа MCM-41. Опубл. 20.11.2006. [Patent 2287485 RU. Belousov O.V., Parfenov V. A., Solov'ev L.A., Kirik S.D. Method for accelerated preparation of mesoporous and mesostructured mcm-41 type silicate materials.Publ. Date20.11.2006 (In Russ.)]

17. Патент 2447022 РФ. Парфенов В.А., Кирик С.Д. Способ стабилизации мезоструктуры силикатных материалов типа МСM-41. Опубл. 10.04.2012. [Patent 2447022 RU. Parfenov V.A., 
Kirik S.D. Method of Stabilising Mesostructure of MCM-41 Type Silicate Materials. Publ. Date 10.04.2012 (In Russ.)]

18. Kirik S.D., Parfenov V.A., Zharkov S.M. Monitoring MCM-41 synthesis by X-ray mesostructure analysis. Microporous and mesoporous materials. 2014, Vol. 195. P. 21-30.

19. Zhao D.Y, Huo Q.S, Feng J.L, Chmelka B.F, and Stucky G.D. Nonionic triblock and star diblock copolymer and oligomeric surfactant syntheses of highly ordered, hydrothermally stable, mesoporous silica structures. Journal of American Chemical Society 1998. Vol. 120(24). P. 6024-6036.

20. Rietveld H. M. The Profile refinement method for nuclear and magnetic structure. Journal of Applied Crystallography 1969. Vol. 2. P. 65-71.

21. Solovyov L. A. , Kirik S. D. , Shmakov A. N., and Romannikov V. N. A continuous electron density approach in Rietveld analysis for structure investigations of the mesoporous silicate materials. Advances in X-ray analysis. 2001. Vol. 44. P. 110-115.

22. Solovyov L. A. Full-profile refinement by derivative difference minimization. Journal of Applied Crystallography. 2004. Vol. 37. P. 743-749.

23. Тарабанько В. Е., Смирнова М. А., Челбина Ю. В. , Черняк М. Ю. Низкотемпературный синтез 5-гидроксиметилфурфурола. Химия растительного сырья 2011. №1. С. 87-92. [Tarabanko V. E. , Smirnova M. A., Chelbina Yu. V., Chernyk M. Yu. Low-temperaturesynthesisof 5-hydromethylfurfural. Khimija Rastitel'nogo Syr’ja. 2011. N. 1. P. 87-92. (In Russ.)]

24. Kuzmic P. Program DYNAFIT for the Analysis of Enzyme Kinetic Data: Application to HIV Proteinase. Analytical Biochemistry. 1996. Vol. 237(2). P. 260-273. 